\title{
Teaching Information Quality in Information Systems Undergraduate Education
}

\author{
Omar E. M. Khalil \\ University of \\ Massachusetts, \\ Dartmouth

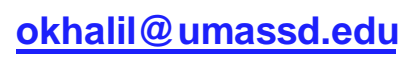

\author{
Diane M. Strong \\ Worcester \\ Polytechnic Institute

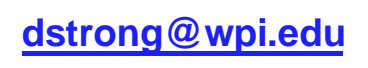

\author{
Beverly K. Kahn \\ Suffolk \\ University
}

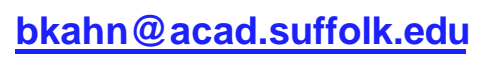

\author{
Leo L. Pipino \\ University of \\ Massachusetts, Lowell
}

\begin{abstract}
Authors discuss and present an information quality framework from the literature on data and information quality. They identify important information quality competencies derived from the framework. Two recent Information Systems (IS) curriculum models are examined to determine the extent to which they include these competencies. The result is a documentation of the gap between the two IS curriculum models and the information quality needs of organizations. Authors suggest ways as to how to close this gap and improve information quality teaching and learning.
\end{abstract}

Keywords: IS curriculum models, information quality, data quality, total quality management

\section{Introduction}

Poor data and information quality can have a significant negative impact on organizations' success. Consequently, organizations are implementing programs to improve data quality to achieve competitive advantage (Redman 1995; 1996). Such improvement programs are critical for the development and maintenance of data warehouses, which are being built by organizations to improve customer service and managerial decision making. Without proper data quality processes, the data warehouse will begin to accumulate "dirty data" (Garcia 1997).

The expectations of information consumers (people who use information) go beyond accurate and factually correct data. Information consumers expect the information custodians (IS professionals responsible for managing the organization's data and information resources) to provide systems (1) that are responsive, (2) that deliver relevant and easily interpreted information, (3) that provide flexible, easily aggregated, and easily manipulated data, and (4) that are secure and robust enough to prohibit accidental or intentional data corruption (Mathieu and Khalil 1997; Strong, Lee and Wang 1997a). As a consequence, IS professionals must seek not only to improve data accuracy, but also to ensure information accessibil-

Material published as part of this journal, either on-line or in print, is copyrighted by the publisher of Informing Science. Permission to make digital or paper copy of part or all of these works for personal or classroom use is granted without fee provided that the copies are not made or distributed for profit or commercial advantage AND that copies 1) bear this notice in full and 2) give the full citation on the first page. It is permissible to abstract these works so long as credit is given. To copy in all other cases or to republish or to post on a server or to redistribute to lists requires specific permission and payment of a fee. Contact Editor@inform.nu to request redistribution permission. ity and relevance as it relates to the context of the information consumers' tasks (Wang and Strong 1996; Strong, Lee and Wang 1997b).

Few IS professionals, however, have received formal training in specific techniques to maintain and improve information quality. What techniques they are taught are often presented in an ad hoc way as part of technical IS courses. For example, they may learn about concepts such as entity integrity and referential integrity that contribute to information quality.

The important issue of information quality (IQ) is not addressed directly in most IS curriculum models. IS curricula in most universities give it little attention and leave the teaching of IQ to individual faculty preferences and initiatives. At best, IS students are exposed to topics that impact IQ, but they are not equipped with a broad understanding of the principles behind measuring, analyzing and improving IQ in an organization. Further, IS students do not receive instruction on the overall role of IQ in the design and implementation of information systems, databases, and data warehouses (Mathieu and Khalil 1997). This comes at a time when IS professionals are increasingly becoming responsible for their organization's IQ.

There appears to be a mismatch between the needs of organizations for delivering high-quality information to information consumers and the skills of new IS professionals graduating from universities in business and management programs. This paper examines this mismatch in detail and makes recommendations on closing the gap and improving IQ teaching and learning. 


\section{A Model of Information Quality}

High quality information is information that is fit for use by information consumers (Strong, Lee and Wang 1997b). This definition follows directly from the standard fitness-for-use product quality aspect of information addresses the tangible measures of freedom from errors, completeness, and consistency whereas the service quality aspect of IQ addresses the intangible measures of ease of manipulation, security, and accessibility of the information to consumers. Along the qual-

\begin{tabular}{|c|c|c|}
\hline & $\begin{array}{l}\text { Conforms to } \\
\text { Specifications }\end{array}$ & $\begin{array}{c}\text { Meets or Exceeds } \\
\text { Consumer Expectations }\end{array}$ \\
\hline $\begin{array}{l}\text { Product } \\
\text { Quality }\end{array}$ & $\begin{array}{ll} & \text { Sound Information } \\
\text { IQ Dimensions: } \\
\text { - Free-of-Error } \\
\text { - Concise Representation } \\
\text { - Completeness } \\
\text { - Consistent Representation }\end{array}$ & \begin{tabular}{ll} 
& \multicolumn{2}{c}{ Useful Information } \\
IQ Dimensions: \\
- Appropriate Amount \\
- Relevancy \\
- Understandability \\
- Interpretability \\
- Objectivity
\end{tabular} \\
\hline $\begin{array}{l}\text { Service } \\
\text { Quality }\end{array}$ & $\begin{array}{l}\text { Dependable Information } \\
\text { IQ Dimensions: } \\
\text { - Timeliness } \\
\text { - Security }\end{array}$ & $\begin{array}{ll} & \text { Usable Information } \\
\text { IQ Dimensions: } \\
\text { - Believability } \\
\text { - Accessibility } \\
\text { - Ease of Operation } \\
\text { - } \quad \text { Reputation }\end{array}$ \\
\hline
\end{tabular}

Table 1: The PSP/IQ Model (Kahn and Strong, 1998)

definition for products and services (Deming 1986; Juran and Gryna 1988; Figenbaum 1991). The Product and Service Performance Model for Information Quality (PSP/IQ Model), shown in Table 1, captures the key quality aspects that are relevant to delivering high-quality information (Kahn and Strong 1998; Kahn, Strong and Wang Forthcoming). It operationalizes the general fitness-for-use definition of IQ.

The PSP/IQ Model is based on constructs from two traditional disciplines. The first is that of total quality management in which two views of quality performance goals are prevalent: quality as conformance to specifications and quality as meeting or exceeding consumer expectations (Reeves and Bednar 1994). The second discipline is that of marketing which distinguishes between product quality and service quality, e.g., (Zeithaml, Berry and Parasuraman 1990). Both product and service quality are important aspects of IQ.

The PSP/IQ model consists of four quadrants that capture how well organizations produce sound and useful information products and deliver dependable and usable information services to information consumers. These four quadrants are formed from two rows, product and service quality, and two columns, conforms to specifications and meets or exceeds customer expectations. Along the product-service axis, the ity-performance axis, conforms to specifications addresses the goals of information producers and IS professionals as captured in information and systems specifications. Meets or exceeds consumer expectations captures the view that information must be useful to the tasks of information consumers.

The quadrants of the PSP/IQ model provide a view of IQ that is meaningful to decision-makers. The sound information or soundness quadrant (product quality/conforms to specifications) captures the concept of the basic characteristics needed to consider information to be of high quality, e.g., being accurate, complete, and free-of-error. For example, a database with 99\% accuracy and completeness of inventory information would have high quality for this quadrant. The dependable information or dependability quadrant (service quality/conforms to specifications) captures the concept of the basic characteristics needed to consider the delivery of information to consumers to be of high quality. For example, if consumers regularly receive inventory information in a timely manner, then the basic service specifications for the information product are met.

The useful information or usefulness quadrant (product quality/meets consumer expectations) captures the concept that an information product can only meet/exceed consumer expecta- 
tions if it is useful and relevant for consumers' tasks. For example, if consumers need inventory information broken down by warehouse location, then the inventory information product is only of high quality if this breakdown exists. The usable information or usability quadrant (service quality/meets consumer expectations) captures the concept that an information service can only meet/exceed consumer expectations if information consumers can easily and conveniently acquire and tailor that service to their needs. For example, consumers must be able to use the query language provided to retrieve easily the specific inventory information they need to make effective decisions.

\section{The Model's Implications for Teaching and Learning IQ}

The PSP/IQ Model can be used to structure what students should be learning to improve information quality in an organization. First, consider the product-service axis. To understand this axis, students must know the characteristics of products and how they differ from the characteristics of services. This is the foundation for understanding how to deliver high-quality products and how to deliver high-quality services. These product and services topics can be found in introductory marketing textbooks and are covered in introductory marketing courses. Marketing texts, however, pay little attention to information as a product or as a service. Thus, the dual character of information as both a product or service is not covered.

Next, consider the quality performance axis. Conforming to specifications and meeting or exceeding customer expectations are TQM topics, which are typically found in an operations or management course, or separate short modules on quality and TQM. While operations courses cover some aspects of services, TQM is still largely focused on manufacturing. It is doubtful that TQM applied to information as a product and as a service is covered in any part of the general management curriculum.

Finally, consider the four cells in the PSP/IQ Model, Sound Information, Dependable Information, Useful Information, and Usable Information. Producing sound information is a primary focus of a course on data management, which is usually required for undergraduate IS majors. Delivering dependable information has elements of IS as well as operations.

Timely and dependable delivery is a logistics topic, although delivering information is probably not included in courses covering logistics. Another aspect of dependable information is security. Techniques for secure information, especially in a database, are covered in the data management course required of all IS majors. Information security is also a topic in the data communications and network management course(s).
Ensuring that the information produced is useful to consumers is a standard topic for IS majors in both systems analysis and design courses and in data management courses. Rapid prototyping is a technique that helps users determine the usefulness and usability of the ensuing information system. System development courses with an implementation project typically include rapid prototyping. The usability of the information is more difficult to place in the curriculum. Usability includes the ability to easily access and manipulate information as needed for tasks. The usability of information may be addressed in a general way in management courses or IS case courses. It may also be apparent in courses addressing reengineering, and process and task improvement. Courses on executive or decision support systems may address usability issues.

To improve the quality of organizational information, many skills are required. Although some of these skills are primarily addressed in courses for IS majors, important concepts such as products and services, TQM, dependable delivery, and information usefulness and usability are topics delivered in the required courses for all management students. IS majors need all these skills, as they become responsible for the quality of an organization's data and information resources.

Many factors influence what students are ultimately taught. Most directly, these factors include the curriculum at the university, the instructor, and the textbook and other materials. Curriculum models, accreditation requirements, and characteristics of the student body in turn influence these. Curriculum models play a key role in promoting the revision and modernization of university curricula and the revision of textbooks to support new curricula.

\section{Data and Information Quality in IS Curriculum Models}

Updated IS curriculum models enable academic communities to maintain programs that are consistent both with employment needs of the business community and with the body of IS knowledge. Model IS curricula also provide for administrative awareness regarding resources, course offerings, computing hardware, software, and laboratory resources needed for a viable program. IS professionals that hire students graduating from programs following a curriculum model have a better understanding and appreciation for each student's knowledge base. 


\section{The IS'97 Curriculum Model}

IS'97 is the latest output from model IS curriculum work that began in the early 1970s (Davis, Gorgone, Couger, Feinstein, \& Longenecker 1997, http://www.acm.org/education/curricula.html). It is the first collaborative curriculum effort of the ACM, AIS, and AITP (formerly DPMA) societies. The IS'97 model provides curriculum guidelines for undergraduate programs in Information Systems, and is designed to prepare graduates to function in entry-level information systems positions with a basis for continued growth. There are ten IS courses (IS'97.1-97.10) in the model, as shown in Table 2. be weak in addressing a key purpose of developing a system, the delivery of sound, dependable, useful, and usable information. As long as the curriculum model focuses on systems, rather than information, information quality is likely to play a minor role. Furthermore, the IS'97 model is a general model, working equally well in management, computer science, or industrial engineering programs. Marketing, operations, and TQM courses typically required in management schools are critical for understanding how to deliver high-quality information to information consumers.

\begin{tabular}{||ll|cl|}
\hline \multicolumn{2}{|c|}{ IS'97 Curriculum Model } & $\begin{array}{c}\text { The Information Resources Management } \\
\text { Curriculum Model (IRMCM) }\end{array}$ \\
\hline IS'97.1 & Fundamentals of Information Systems & IRM1 $\quad$ IRM Principles \\
\hline IS'97.2 & Personal Productivity with IS Technology & IRM2 & Information Systems Technology \\
\hline IS'97.3 & Information Systems Theory and Practice & IRM3 $\quad$ Algorithm Concepts \& Information Management \\
\hline IS'97.4 & Information Technology Hardware and Software & IRM4 & Decision Support Systems \\
\hline IS'97.5 & Programming, Data, File and Object Structures & IRM5 $\quad$ Data Resource Structures \& Administration \\
\hline IS'97.6 & Networks and Telecommunication & IRM6 & IRM Design and Implementation \\
\hline IS'97.7 & Analysis and Logical Design & IRM7 & $\begin{array}{c}\text { Communication Technology and Information } \\
\text { Management }\end{array}$ \\
\hline & & IRM8 & Global Information Management \\
\hline IS'97.8 & Physical Design and Implementation with DBMS & IRM9 & Executive Information Systems \\
\hline IS'97.9 & $\begin{array}{l}\text { Physical Design and Implementation with a } \\
\text { Programming Environment }\end{array}$ & IRM10 & Seminar in IRM \\
\hline IS'97.10 & Project Management and Practice & & IRM1, 2, 3, 5, and 6 are required. \\
\hline \multicolumn{2}{|c|}{ All ten courses are required. } &
\end{tabular}

Table 2: Courses in Two IS Curriculum Models

The IS'97 Model Curriculum places a significant emphasis on quality. In particular, it emphasizes quality in two areas: (1) principles of quality management (in IS'97.3); and (2) software quality (in IS'97.7 and IS'97.9). "Information quality" is mentioned only once (as a topical area in IS' 97.1). This mention, though, has had some effect since new introductory IS texts sometimes mention information quality in their introductory chapter. Precision and representation, as two information quality characteristics, are emphasized for coverage in IS' 97.5 (the programming course).

Surprisingly though, data and information quality is not included among the proposed topical areas in IS'97.8 (the database course). Thus, according to this curriculum model, data and information quality is not perceived to be a critical issue that must be addressed in the design and implementation of information systems and databases. This contrasts with the initiatives of individual faculty that are including data and information quality topics in database management courses.

The IS'97 curriculum model focuses on information technology and systems development and deployment. It appears to

\section{The Information Resources Management Curriculum Model (IRMCM)}

The Information Resource Management (IRM) curriculum model (IRMCM) was published in 1996 as a four-year undergraduate-level program (IRMA 1996, http://www.irmainternational.org/crclm919.html). It is the result of a joint effort by the Information Resources Management Association (IRMA) and the Data Administration and Management Association (DAMA). Its purpose, as stated in the executive summary is:

\footnotetext{
The intention of this curriculum is to prepare students to understand the concepts of information resources management and technologies, methods, and management procedures to collect, analyze and disseminate information throughout organizations in order to remain competitive in the global business world ( $p$. 1).
}

With this focus on "collect, analyze, and disseminate information," it was anticipated that the IRMA/DAMA curriculum model would be more consistent with the PSP/IQ model than IS'97. 
According to IRMCM, knowledge of the use of hardware and software in itself is insufficient for an effective MIS professional. With only this knowledge, students would leave business programs without an appreciation of information management. IRMCM focuses on information as a strategic organizational asset and focuses on the acquisition and application of information. This focus on information is intentional; the developers of the IRMCM believe that IS curricula place too much focus on systems and technology.

Similar to IS'97, the IRMCM model proposes ten courses for an undergraduate degree in IRM, as shown in Table 2. A review of the content of the courses reveals that several courses include some information quality or TQM concepts. For example, IRM1, has "information quality and control," "data vs. information," and "data security and control" as topical areas, but they represents only 5-10\% of the course content. IRM2 builds on IRM1 and includes some information quality topics such as privacy of information. Additionally, TQM is included as one of the proposed topics for IRM6, but at less than $10 \%$ of the total coverage. IRM5 is a typical database management course for management students. IRM6, which follows IRM5 in the curriculum, is a systems life-cycle course from analysis through implementation.

The IRMCM is designed as a major within a management school. In addition to the IRM courses, students take marketing and operations courses where they are likely to cover more material on TQM and general quality concepts. The TQM and quality concepts in the IRM courses can be viewed as applying these general concepts to information and information systems.

\section{Using PSP/IQ Concepts for Assessing the Curriculum Models}

The PSP/IQ model provides a framework for understanding the needs of organizations for sound, dependable, useful, and usable information. It focuses on information and its delivery, not on systems. The important issue for students to understand is that technology is a method for delivering highquality information; technology is not the end goal. Specifically, a system is not the deliverable, the information is. Of the two IS curriculum models, the model developed by IRMA/DAMA is closest to a focus on information and its quality, rather than on systems development. In contrast, the IS'97 curriculum model has more of a systems development focus rather than information delivery.

Both curriculum models include systems development courses. To improve students' understanding of the principles for measuring, analyzing, and improving information quality in organizations, systems and database development courses must place more emphasis on high-quality information as the end goal, rather than a working system as the end goal. Stu- dents need to understand systems development, but they also need to understand that the purpose of developing a system is to deliver information to those who need it. To the extent that these courses currently cover the delivery of high-quality information, the focus is on the product quality aspects rather than the service quality aspects.

In addition to learning to manage the systems development lifecycle, IS majors must also have the skills necessary to implement and manage IQ improvement programs. Clearly, general managers will not be the implementers of specific IQ improvement programs. IS students should be exposed to a more detailed elaboration of the general IQ concepts and to detailed methods and techniques to achieve high-quality information. They should also understand the need for IQ improvement goals to fit the objectives of the organization and the need for integrated, cross-disciplinary management of information production, storage, and use processes. This understanding should include both the product and service aspects of information.

Since these are managerial concepts, a logical place in the curriculum to cover the management of information quality improvement is in a senior-level IS management course. Both curriculum models include such a course, IS'97.10 and IRM10. IS'97.10 focuses entirely on managing systems development. It could also include the management of information delivery and information quality improvement. IRM10 covers information flow processes and information management topics, as well as integration of technology and information topics. It is, however, an elective.

A key difference between the two curriculum models is that the IRMA/DAMA model assumes that it is a major within a business or management curriculum. Specifically, IRM1 is designed as the IS core course required of all management students. The IS'97 curriculum makes no such assumption. All students when they graduate will be making decisions using information, and they should be aware of issues about the quality and validity of this information.

The nature of the surrounding curriculum is important because in management curricula, the required IS course is usually taught at the junior level, with some introduction to productivity tools at the freshman level. In contrast, the required course in liberal arts curricula is designed for the freshman or perhaps the sophomore level. The content of a junior level course is very different from the content of a freshman level course.

The introductory courses in both curriculum models include quality management concepts. This is the logical place for general IQ concepts and awareness in the undergraduate curriculum. In a management curriculum, this integrates IQ concepts with other principles of information systems with the 
Teaching Information Quality

enterprise as the context. Both curricula present quality in the context of total quality management. This covers the columns in the PSP/IQ model, but not the rows.

The rows of the PSP/IQ model, product quality and service quality, are typical topics in a marketing course. Thus, IS majors and minors are likely to be exposed to these topics if the IS curriculum is embedded in a management curriculum. Liberal arts curricula are unlikely to cover such topics. Furthermore, information quality dimensions in the service quality row, especially those related to dependable delivery of information, include aspects of process control and accountability. Process control and quality control are typical industrial engineering or operations management topics, which may be covered in a management curriculum. Accountability and responsibility for control are typical managerial accounting topics, which are part of management curricula but not liberal arts curricula.

Currently, the inclusion of IQ related topics is often based on individual faculty initiatives to communicate to students some practical results from faculty research. In terms of the PSP/IQ model, faculty initiatives still primarily focus on the product aspects of information quality rather than the service aspects. The more critical issue, however, is to examine what should be taught in both the IS curriculum and the management curriculum about IQ.

\section{Conclusion}

There appears to be a mismatch between the information quality (IQ) needs of organizations and the IQ skills of IS graduates. The two IS curriculum models reviewed here do little to address this mismatch. While individual faculty initiatives have included IQ skills in data management courses, a broader approach to including IQ in the curricula is necessary to provide the IQ skills organizations need.

General concepts of IQ as embedded in the Product Service Performance Model for Information Quality (PSP/IQ Model), and the management of an IQ improvement cycle, should be taught to all management students. IS majors need a more indepth treatment of these concepts in an IS management course as well as detailed techniques for measuring, managing, and improving IQ in database and systems analysis and design courses.

Such changes in the IS curriculum would provide both IS majors and management students with the concepts and skills to meet the needs of organizations for improved information quality. These changes, however, will need to become widespread with corresponding changes to IS textbooks for introductory, database, systems analysis and design, and information management courses.

\section{Recommendations}

The following recommendations are made for improving IS curricula so that undergraduates have the skills necessary for understanding information quality issues and for measuring, analyzing, and improving the quality of information delivered to information consumers.

- $\quad$ The required introductory course for all management majors should include information quality concepts and awareness, in addition to total quality management.

- Database and systems development courses must add a focus on high-quality information as the deliverable, rather than the implied focus of a system as the deliverable.

- Senior-level IS managerial-oriented courses should include topics about managing an information quality improvement cycle.

- Topics such as information as a product and service, management and quality control of information processes, should be covered in non-IS courses, such as marketing, managerial accounting, and operations.

- Existing textbooks for database management, systems analysis and design, introduction to information systems, and other relevant management courses must be modified to support the topics identified above.

- For IS curricula outside of management programs, the information quality aspects included in marketing, managerial accounting, and operations courses need to be covered, probably in a senior IS capstone course.

To ensure that students acquire these skills, it is important to educate the educators about data and information quality. Typical methods of diffusion of new information to educators are changes in textbooks and published research papers. Thus, the IQ content of relevant textbooks must be increased. We sampled 28 recently published database, systems analysis, and introductory IS texts provided to the authors by publishers for evaluation for use in courses. Less than one-third mentioned quality in any way. One text discussed data quality, one information quality. While general quality references are probably more common in introductory marketing and operations textbooks, they are unlikely to mention data or information quality.

There are also approaches for educating the educators. Educators can attend an IQ-oriented panel at a conference, such as the IRMA and the ICIS conferences. Panelists often provide recommendations based on their experiences, which may be directly applicable to educators. On the other hand, the educational environment of the panelists may differ substantially from that of other educational institutions. At such general conferences, only one panel or session on information quality may be included. 
Another approach for educators is to attend a conference on IQ such as the annual information quality conference (Wang 1996; Strong and Kahn 1997; Chengalur-Smith and Pipino 1998). At this conference, all presentations focus on information quality research and practice. Educators can discuss information quality topics with presenters and participants and apply what is learned in their courses. For an educator whose research interests are not related to information quality, a three-day off-site commitment to information quality topics may be unreasonable. Also, the educator could take a specialized course such as the annual Total Data Quality Management summer course at MIT. This provides the most detail and provides materials that can be directly incorporated into one or more courses. It is also longer and more expensive than the information quality conference.

\section{References}

Chengalur-Smith, I., \& Pipino, L. L., Eds. (1998). Proceedings of the 1998 Conference on Information Quality. Cambridge, MA: Massachusetts Institute of Technology.

Davis, G. B., Gorgone, J. T., Couger, J. D., Feinstein, D. L., \& Longenecker, Jr., H. E. (1997). IS'97 Model Curriculum and Guidelines for Undergraduate Degree Programs in Information Systems. New York, NY: Association for Computing Machinery (ACM), Association for Information Systems (AIS), and Association of Information Technology Professionals (AITP, former DPMA). Available: hittp://www.acm.org/education/curricula.html. (May 11, 1999).

Deming, W. E. (1986) Out of Crisis. Cambridge, MA: MIT Press.

Feigenbaum, A. V. (1991) Total Quality Controli New York, NY: McGraw-Hill.

Garcia, M. R. (1997). Taking Care of Your Warehouse. Beyond Computing, $64,32-36$.

IRMA (1996). The Information Resources Management Curriculum Model. Hershey, PA: Information Resources Management Association and Data Administration and Management Association. Available:ihttp://WWW. irma-international.org . (May 11, 1999).

Juran, J. M., \& Gryna, F. M. (1988) ¿Quality Control Handbool.. New York, NY: McGraw-Hill.
Kahn, B. K., \& Strong, D. M. (1998). Product and Service Performance Model for Information Quality: An Update. 1998 Conference on Information Quality. Cambridge, MA: Massachusetts Institute of Technology.

Kahn, B. K., Strong, D. M., \& Wang, R. Y. (Forthcoming). Information Quality Benchmarks: Product and Service Performance. Communications of the ACM.

Mathieu, R., \& Khalil, O. E. M. (1997). Teaching Data Quality in the Undergraduate Database Course. 1997 Conference on Information Quality. Cambridge, MA: Massachusetts Institute of Technology.

Redman, T. C. (1995). Opinion: Improve Data Quality for Competitive Advantage. Sloan Management Review, 36 2, 99-107.

Redman, T. C. (1996). Data Quality for the Information Age. Norwood, MA: Artech House.

Reeves, C. A., \& Bednar, D. E. (1994). Defining Quality: Alternatives and Implications. Academy of Management Review, 19 3, 419445 .

Strong, D. M., \& Kahn, B. K., Eds. (1997). Proceedings of the 1997 Conference on Information Quality. Cambridge, MA: Massachusetts Institute of Technology.

Strong, D. M., Lee, Y. W., \& Wang, R. Y. (1997a). 10 Potholes in the Road to Information Quality. IEEE Computer, 30 8, 38-46.

Strong, D. M., Lee, Y. W., \& Wang, R. Y. (1997b). Data Quality in Context. Communications of the ACM, 40 5, 103-110.

Thomson, N. S. (1994). Using TQM Principles to Teach Current Topics, in Information Systems, Journal of Information Systems Education, 62. 65-69.

Wang, R. Y., Ed. (1996). Proceedings of the 1996 Conference on Information Quality. Cambridge, MA: Massachusetts Institute of Technology.

Wang, R. Y., \& Strong, D. M. (1996). Beyond Accuracy: What Data Quality Means to Data Consumers. Journal of Management Information Systems, $124,5-34$.

Zeithaml, V. A., Berry, L. L.. \& Parasuraman, A. (199b). Delivering! Quality Service: Balancing Customer Perceptions and Expectaiions. New York, NY Free Press. 